\title{
High-Speed Optical Sorting of Soft Wheat for Reduction of Deoxynivalenol
}

\author{
Stephen R. Delwiche, USDA/ARS, Beltsville Agricultural Research Center, Instrumentation and Sensing Labora- \\ tory, Building 303, BARC-East, Beltsville, MD 20705-2350; and Thomas C. Pearson and Daniel L. Brabec, \\ USDA/ARS, Grain Marketing and Production Research Center, 1515 College Ave., Manhattan, KS 66502
}

\begin{abstract}
Delwiche, S. R., Pearson, T. C., and Brabec, D. L. 2005. High-speed optical sorting of soft wheat for reduction of deoxynivalenol. Plant Dis. 89:1214-1219.

Fusarium head blight (FHB) is a fungal disease that affects small cereal grains, such as wheat and barley, and is becoming more prevalent throughout much of the world's temperate climates. The disease poses a health risk to humans and livestock because of the associated production of the mycotoxin deoxynivalenol (DON or vomitoxin) by the causal organism, Fusarium graminearum. A study was undertaken to examine the efficiency of high-speed, optical sorting of intact wheat (Triticum aestivum) kernels for reduction of DON concentration. Soft red winter ( $n$ $=32)$ and soft white $(n=3)$ wheat samples, known to have elevated levels of FHB, were obtained from commercial mills throughout the eastern United States. An additional seven samples of wheat from the discard piles of in-mill cleaners were also studied. Fusarium-damaged wheat, cleaned of nonkernels and foreign material $(\sim 4.5 \mathrm{~kg} / \mathrm{sample}$, DON range $=0.6$ to $20 \mathrm{mg} / \mathrm{kg})$, was fed into a commercial high-speed bichromatic sorter operating at a throughput of 0.33 $\mathrm{kg} /$ (channel-min) and a kernel rejection rate of $10 \%$. A wavelength filter pair combination of 675 and 1,480 $\mathrm{nm}$ was selected for sorting, based on prior research. Visual measurements of the proportion of Fusarium-damaged kernels were collected on incoming and sorted seed (separate analyses of accepted and rejected portions), as were measurements of DON concentration. Results indicated that the fraction of DON contaminant level in the sorted wheat to that in the unsorted wheat ranged from 18 to $112 \%$, with an average of $51 \%$. Nine of the 35 regular samples and all seven of the discard pile samples underwent a second sort, with five from this second set undergoing a third sort. Multiple sorting was effective in producing wheat whose DON concentration was between 16 and $69 \%$ of its original, unsorted value.
\end{abstract}

Additional keyword: scab

Fusarium head blight (FHB), also known as scab, is a fungal disease that affects small grains (wheat, barley, oats, rye) and occurs in the temperate growing regions throughout the world. In North America, it is primarily caused by the fungus Fusarium graminearum infecting the flowers and subsequently causing disease in the developing seed. This results in lower yields due to loss during mechanized harvesting (2), low test weight (6), and diminished baking characteristics (10). More importantly, FHB is a food safety concern, primarily because of the metabolite, deoxynivalenol (DON), also known as vomitoxin (21). This Type B trichothecene mycotoxin is known to cause sickness

Corresponding author: S. R. Delwiche

E-mail: delwiche@ba.ars.usda.gov

Mention of trade names or commercial products is solely for the purpose of providing specific information and does not imply endorsement or recommendation by the USDA.

Accepted for publication 6 July 2005.

\section{DOI: 10.1094/PD-89-1214}

This article is in the public domain and not copyrightable. It may be freely reprinted with customary crediting of the source. The American Phytopathological Society, 2005. (including vomiting, feed refusal, bloody diarrhea, dermatitis, hemorrhaging, and death) in nonruminant animals, especially swine. The biochemical mode of action is attributed to the inhibition of DNA, RNA, and protein synthesis at the ribosomal level (22). DON is considered a health risk to humans. In the United States, the authority to regulate mycotoxins is codified in the Federal Food, Drug and Cosmetic Act, which places authority with the Food and Drug Administration (FDA). Certain mycotoxins, such as aflatoxin, a recognized carcinogen, are regulated by establishment of action levels, which can then necessitate official testing for the mycotoxin and can result in the condemnation of grain lots in excess of the action level. Other mycotoxins, including DON, are not regulated by FDA per se, but instead are voluntarily controlled under the guidelines of advisory levels. Depending on the intended use, the advisory level for DON in the United States ranges from $1 \mathrm{mg} / \mathrm{kg}$ (finished wheat products destined for human consumption) through $5 \mathrm{mg} / \mathrm{kg}$ (nonruminant animals, not exceeding $20 \%$ [swine] or $40 \%$ [others] of the diet) to $10 \mathrm{mg} / \mathrm{kg}$ (ruminating beef and feedlot cattle older than 4 months and chickens, not exceeding 50\% of the diet) (28). Outside of the United States, many countries have established equivalent guidelines, and in some jurisdictions, such as the European Commission, consideration has been given to establishing the human food limit for DON at $0.5 \mathrm{mg} / \mathrm{kg}$ for finished products and 0.75 $\mathrm{mg} / \mathrm{kg}$ for flour as a raw material in food products (5). Approximately 100 countries have established varying degrees of regulations for mycotoxins, inclusive of DON (14). Quality and safety aspects of DON and other trichothecenes are the subjects of a recent review (11).

Although FHB has been observed since at least the late 1800s (26), its prevalence appears to be increasing in recent years for uncertain reasons, although increased use of minimum tillage and corn in the crop rotation are thought to be major contributors. Outbreaks in North America include those in the early 1980s, the early and mid1990s, such as in the Midwest in 1996 (15), and lately, the 2003 and 2004 seasons in the soft red winter growing regions of the eastern United States. A conventional postharvest method for reduction of DON is grain blending, in which the contaminant is diluted through combination with a cleaner lot. This practice could be banned in the United States should the FDA decide to regulate DON with an action level. Other methods include screening and aspiration techniques, which rely on general seed size and weight differences (25), and specific gravity tables, which rely on density differences (27), each with partial effectiveness.

In recent years, research has also addressed Fusarium-damaged kernel (FDK) detection by optical measurement. Both image analysis and near-infrared (near-IR) spectroscopies have been utilized. In the imaging studies, kernel morphology and color characteristics were the primary features used to distinguish damaged from healthy kernels $(17,23)$, with the Fusarium damage characterized by kernels having a white or pinkish color and being shriveled (1). Near-IR spectroscopic measurement of DON was initially addressed by Dowell et al. (13). In subsequent spectroscopy studies, Delwiche and co-workers demonstrated that identification of FDK in hard red winter wheat was possible at 95 to $97 \%$ accuracy with as few as two wavelengths $(7,9)$. A recent investigation examined the condition of a two-wavelength linear discriminant analysis, such that one wavelength from the visible region (410 to $865 \mathrm{~nm})$ and one from the near-IR region $(1,032$ to $1,674 \mathrm{~nm})$ were selected $(8)$. The 
two-wavelength limit was imposed for the purpose of patterning the laboratory system's optical characteristics with those of commercial high-speed sorters. Exhaustive searches were performed to identify the wavelength regions that maximized classification accuracy. Although accuracy was high (86 to $97 \%$, depending on wavelength region), the low throughput of this spectroscopy-based system makes it unsuitable for commercial operation. However, findings on optimal wavelengths can consequently be matched with filter pairs used in commercial sorters.

High-speed wheat sorting studies have included the separation of red from white kernels (18), low and high protein kernels (19), and removal of kernels infected with Karnal bunt (Tilletia indica) (12). Use of this technology for removal of Fusariumdamaged corn kernels, with accompanying analytical measurements of aflatoxin and fumonisin (B1 + B2 + B3), was recently reported (20). To date, however, no such studies have been reported for Fusariumdamaged wheat. Therefore, the study described herein was designed to examine high-speed optical sorting in wheat (Triticum aestivum) for removal of FDK and reduction of DON.

The objective of this study was to quantify the level of DON reduction in soft red winter wheat subjected to high-speed optical sorting. Commercial wheat samples were utilized for the purpose of mimicking the prevailing conditions in commercial wheat of moderate to high Fusarium damage.

\section{MATERIALS AND METHODS}

Wheat. Thirty-five samples, each $\sim 4.5$ $\mathrm{kg}$, of primarily (32 samples) soft red winter wheat, with the balance (3 samples) of soft white, were obtained from commercial mills and elevators located in six states in the eastern United States. All samples, except one, were from the 2003 harvest. An additional seven samples were supplied by mills from the discard piles of wheat that had undergone cleaning by screening or aspiration. These additional samples (hereafter, the "discard samples") tended to be markedly higher in level of Fusarium damage and were consequently considered separately. All samples were received in spring 2004 and stored at $0^{\circ} \mathrm{C}$ or cooler until the 1-month period of sorting trials. Because of their commercial nature, nearly all samples were composites of two or more varieties, with the following varieties listed in order of their prevalence (as defined by the numbers of samples that contained a variety at greater than $10 \%$, identified visually by the USDA GIPSA FGIS Board of Appeals and Review): 'Elkhart', 'Madison', 'Pioneer 2552', 'Coker', 'Clark', 'Roane', 'Ernie', 'FFR 525 W', 'Cardinal', 'Harus', 'Penewawa', and 'Cashup'.

Equipment. A commercial high-speed optical sorter (ScanMaster II 2000 DE;
Satake-USA, Houston, TX), with capability of measurement at two wavelengths (typically termed bichromatic sorters), was used in this study. This sorter consists of eight banks of 10-channel steeply inclined chutes, of which four channels of one bank, with six channels blocked, were used in the study. Kernels in a single stream in each channel descend by force of gravity. Immediately below the channel exit, two sensors, one silicon and one indium gallium arsenide (InGaAs), observe each kernel in freefall. A similar pair of sensors examines the kernel from its opposite side. A yellowish ('marigold') background was used to enhance the contrast between normal and diseased kernels. A kernel whose reflectance signal lies outside the useradjusted thresholds for any one of the four detectors is identified as a cull, whereupon an air ejector diverts the kernel from its normal trajectory to a bin for rejected material (hereafter, the "rejects"). Nondiverted kernels (hereafter, the "accepts") fall into a separate bin. Delay time (elapsed time between when a sensor identifies a cull and when the ejector is actuated) and dwell time (length of time the ejector remains on) were 125 and $20 \mathrm{~ms}$, respectively.

Feed rate, as set by vibratory frequency of the takeaway from an inlet hopper, was adjusted to $0.33 \mathrm{~kg} /(\mathrm{min}$-channel). Interference filters centered at 675 and 1,480 $\mathrm{nm}$ (30-nm full-width half maximum) were selected for use in conjunction with the silicon and InGaAs detectors, respectively, based on a recent spectroscopy study (8), which reported on exhaustive searches of the best wavelength pairs to use in wheat kernel Fusarium sorting. Thresholds for the detectors were adjusted

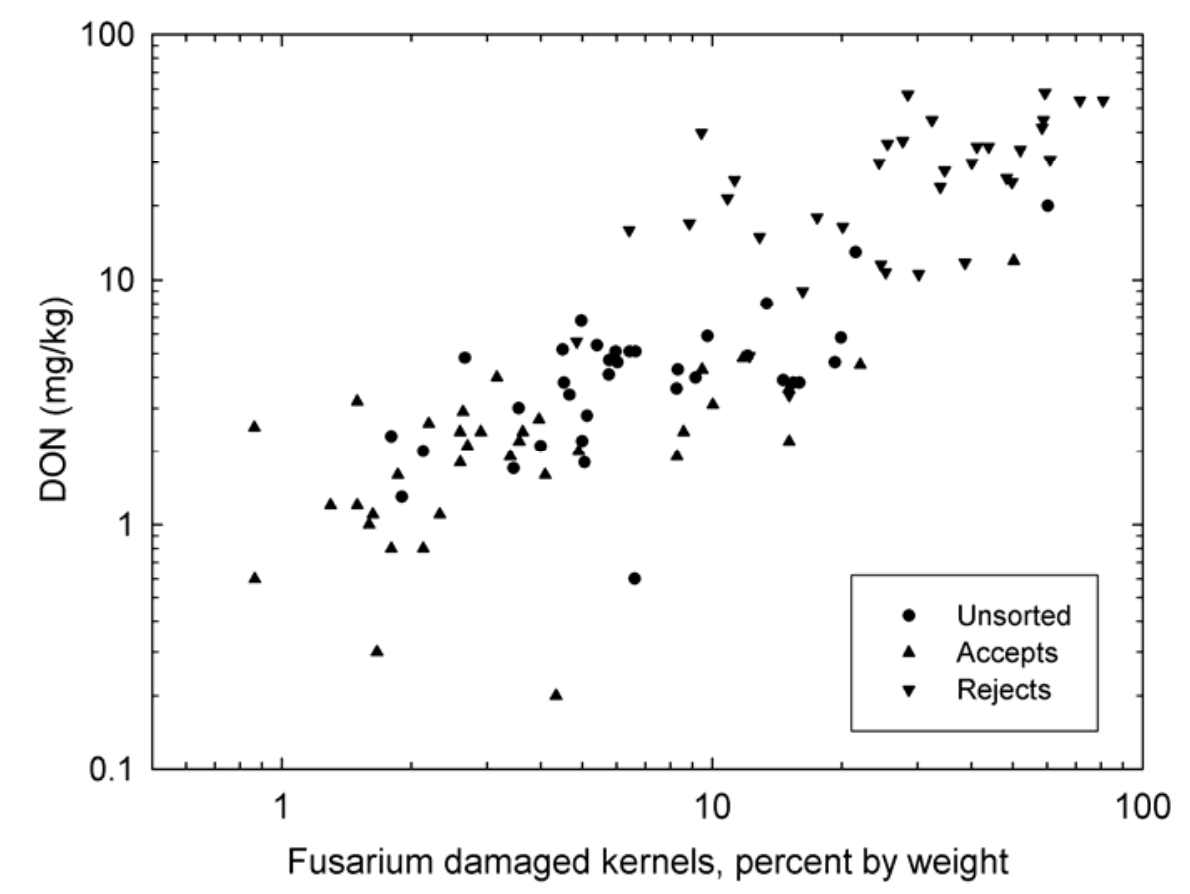

Fig. 1. Relationship between deoxynivalenol (DON) concentration and Fusarium-damaged kernels. by trial and error on each sample to maintain a nominal $10 \%$ by weight overall rejection rate.

Procedure. Each sample was cleaned of straw, glumes, fines, and other foreign material by a Carter-Day dockage tester (Seedburo, Chicago, IL). A Boerner divider (Seedburo) was used to obtain a 100$\mathrm{g}$ test sample for later visual and chemical (DON) analysis. Cleaned material was loaded into the intake hopper of the sorter, whereupon the detector threshold settings tervals, weighing the portions of accepted and rejected material, adjusting the threshold values, recombining through mixing by hand, and recycling material to the hopper as needed until a $10 \%$ rejection rate was attained. All material was then recombined, mixed by hand, and returned to the hopper for the actual sort run. Upon actual sorting, the wheat from each bin was successively divided to obtain a $100-\mathrm{g}$ portion each of accepts and rejects that was set aside for later visual and DON analysis. The balance of each bin was bagged for possible further sorting (described below). At a nominal feed rate of $1.3 \mathrm{~kg} / \mathrm{min}$, sorting occurred over a 3-min period. The nonsteady periods at startup and finish, each lasting approximately $10 \mathrm{~s}$, were not treated separately, based on previous work that found no significant differences between transient and steady-state periods in sorting performance (18).

Of the original 35 samples, 9 contained more than $10 \%$ FDK. These samples were designated for additional sorting. Upon completion of all first sorts, the accepts from these samples were sorted again using the same protocol. For the 7 discard samples (all with FDK > 10\%), the sorting were set by running the sorter in $60-\mathrm{s}$ in- 
protocol was identical to that of the 35 regular samples, with all 7 receiving a second sort and 5 receiving a third sort.

Percentage of Fusarium-damaged kernels. Each test sample was split once, such that one-half $(\sim 50 \mathrm{~g})$ was ground in a cyclone mill (1-mm screen; Udy, Fort Collins, CO) for DON analysis. The other half was split again, whereupon two 15-g portions were weighed out for visual inspection. Inspection consisted of handpicking each portion's kernels for shriveling, weighing the damaged kernels, calculating the percentage by weight of FDK, and then averaging the duplicates. Based on the duplicate values, the FDK repeatability relative standard deviation $\left(\mathrm{RSD}_{\mathrm{r}}\right)$ (16) was $14 \%$.

DON analysis. Determination of DON was performed by ELISA test kit (Ridascreen R5902; R-Biopharm, Inc., Marshall, MI) on 50-g ground portions in $250 \mathrm{ml}$ of distilled water, performed according to the kit directions, briefly described herein. After reaction of the sample solution with a peroxidase-conjugated deoxynivalenol within the antibody coated well (30 $\mathrm{min}$ incubation, followed by washing with a 10 $\mathrm{mM}$ phosphate buffer with $0.05 \%$ Tween $20, \mathrm{pH} 7.4$ ), absorption readings of the microwells containing the substrate/ chromogen with $1 \mathrm{~N}$ sulfuric acid stop solution were measured at $450 \mathrm{~nm}$, referenced to an air blank, using a Stat-Fax Model 303 Plus reader (Awareness Technology, Palm City, FL). Dilution was performed when needed on the samples with high ( $>6$ $\mathrm{mg} / \mathrm{kg}$ ) DON concentration, whereby the filtrate was further diluted to bring the absorption value within the operating range, with the result multiplied by the dilution factor. Precision of this method, as defined by the standard deviation of 26 measurements of a check sample (mean DON $=2.8$ $\mathrm{mg} / \mathrm{kg}$ ) during the 1 -week test period, was $0.4 \mathrm{mg} / \mathrm{kg}$. Based on the manufacturer's information, the kit is sensitive to both DON and 3-acetyl-DON, but has low or no measurable reactivity to other related substances such as nivalenol, 15-acetyl-DON, triacetyl-DON, triacetyl-nivalenol, tetraacetyl-DON, and fusarenon-X.

The efficiency of sorting was calculated for each sample as the ratio of the DON concentrations of the sorted accepts to the unsorted (incoming) seed. Likewise, a similar ratio was calculated for the sorted rejects. Finally, linear regression was used to estimate the maximum levels of DON that could occur in a wheat lot prior to sorting, based on a working assumption that wheat before milling must contain no more than $2 \mathrm{mg} / \mathrm{kg}$ DON in order to produce flour possessing less than $1 \mathrm{mg} / \mathrm{kg}$ DON.

\section{RESULTS}

Single sort. Seed in the accepts bin had a noticeable appearance of less damage compared with the unsorted material. Even more striking was the appearance of the seed from the rejects bin, which, for several of the 35 regular samples, was in excess of $60 \%$ Fusarium damaged. Perfect segregation of normal and Fusarium- damaged kernels is not achievable for two primary reasons: a limitation in optical sensitivity such that kernels of low contrast between normal and damaged condition are mistakenly recognized as belonging to the opposite category; secondly, a mechanical limitation of high-speed sorters, which is that neighboring kernels of identified rejects during freefall are often diverted by the ejector's air burst. Irrespective of whether the test portions for DON analysis were drawn from incoming stock or the sort bins, wheat with large fractions of FDK also tended to have high levels of DON (Fig. 1). DON concentrations of unsorted stock ranged from 0.6 to 20 $\mathrm{mg} / \mathrm{kg}$. Concentration ranges of sorted samples were 0.2 to $12 \mathrm{mg} / \mathrm{kg}$ for the accepts and 3.4 to $58 \mathrm{mg} / \mathrm{kg}$ for the rejects.

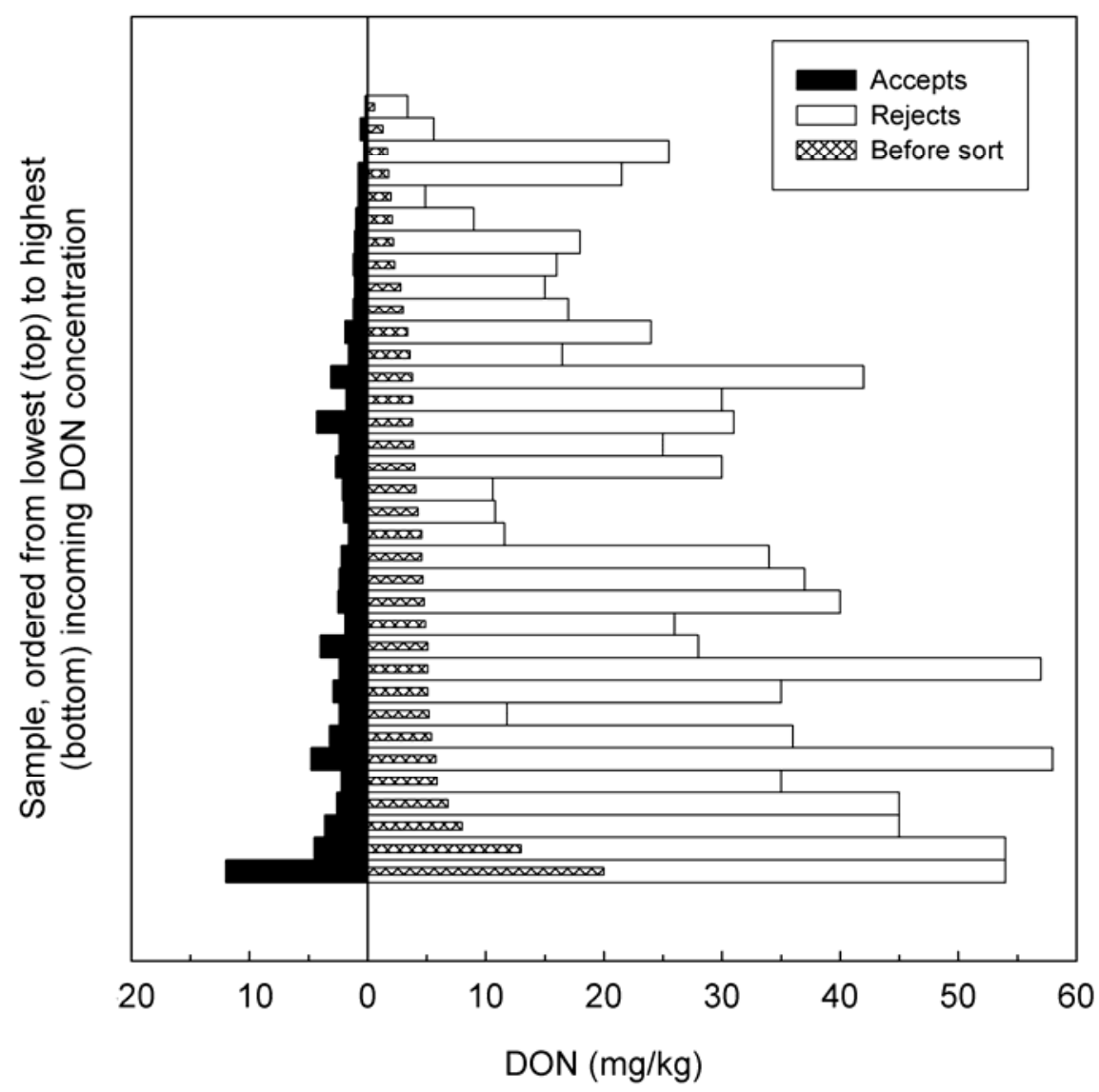

Fig. 2. Deoxynivalenol (DON) concentrations of regular samples $(n=35)$ in the following states of sorting: before sorting, sorted accepts, and sorted rejects.

Table 1. Summary statistics of high-speed sorting

\begin{tabular}{|c|c|c|c|c|c|c|c|}
\hline \multirow[b]{3}{*}{ Category $^{b}$} & \multirow[b]{3}{*}{$\mathbf{N}$} & \multirow{2}{*}{\multicolumn{2}{|c|}{$\begin{array}{l}\text { Weight fraction rejected } \\
\text { by optical sorter }(\%)\end{array}$}} & \multicolumn{4}{|c|}{ Ratio of DON ${ }^{\mathrm{a}}$ in sorted fraction to DON in unsorted fraction $(\%)$} \\
\hline & & & & \multicolumn{2}{|c|}{ Accepts fraction } & \multicolumn{2}{|c|}{ Rejects fraction } \\
\hline & & Mean & Std & Mean & Std & Mean & Std \\
\hline Regular & 35 & 10.6 & 0.47 & 51.1 & 17.3 & 647 & 293 \\
\hline Reds & 32 & 10.7 & 0.47 & 51.6 & 18.0 & 655 & 304 \\
\hline Whites & 3 & 10.4 & 0.22 & 46.1 & 6.1 & 564 & 132 \\
\hline Discarded & 7 & 11.1 & 0.52 & 71.0 & 25.8 & 355 & 214 \\
\hline
\end{tabular}

${ }^{a}$ Deoxynivalenol.

${ }^{\mathrm{b}}$ Regular wheat samples were drawn from material at the elevator or mill in which the material was known to have elevated levels of Fusarium head blight. These samples are also listed by color class. Discarded samples were drawn from the discard piles of mechanical and aspiration cleaning equipment. 
On average $(n=35)$, with a mass rejection rate of $10.6 \%$, the ratio of DON concentrations of accepts to unsorted, expressed as a percent, was $51 \%$, while that of the rejects was $650 \%$ (Table 1). Because white wheats (46 and $560 \%$, respectively, $n=3$ ) had similar segregation performance to red wheats (52 and $650 \%$, respectively, $n=32$ ), these groups were combined in all remaining analyses. Actual concentrations for each sample, before and after sorting, are shown graphically in Figure 2. With respect to unsorted material, the DON concentrations of the accepts were lower in all except one sample, while the concentrations of the rejects were 2 to 15 times higher. The individual DON concentration ratios (expressed as percents), accepts to unsorted, are plotted against the unsorted concentrations in Figure 3. Thirty of the 35 samples had ratios between 30 and $70 \%$, with no trend evident in DON removal efficiency as a function of DON level.

Multiple sorts. For the nine regular samples that underwent a second sort, DON concentrations of accepts were further reduced in a pattern similar to the first sort (Fig. 4). The DON ratio of second sort accepts to first sort accepts, expressed as a percent, ranged from 45 to $92 \%$, with an average of $61 \%$. This ratio was not statistically different (by paired $t$ test) than the DON ratio of the first sort accepts to unsorted material. With respect to the original unsorted material (i.e., DON ratio of second sort accepts to unsorted material), the range and average were 18 to $55 \%$ and $37 \%$, respectively. None of these ratios were correlated to DON level. In absolute units, DON concentration, after two sorts, was reduced to $<3 \mathrm{mg} / \mathrm{kg}$ in all but one sample. Thus, successive sorting of Fusarium-damaged but otherwise ordinary wheat appears to offer the potential of successively reducing DON concentration to less than the FDA advisory level; however, the advantage of resorting must be weighed against the loss in material $(10 \%$ for each sort), assuming that the rejected wheat is of low economic value.

Five of the seven samples that originated from discarded material from wheat cleaners (i.e., not part of the 35 samples) underwent a third sort, with the remaining two samples receiving two sorts. Similar to the nine regular samples that underwent two sorts, DON was reduced in each successive sort of these seven samples, with the exception of the highest contaminated sample, which showed an increase in DON concentration from the unsorted to the first sort accepts (Fig. 5). Even with this discarded material, with the exception of the very heavily damaged wheat (FDK $\geq$ $80 \%$ ), two to three successive sorts resulted in wheat having $<4 \mathrm{mg} / \mathrm{kg}$ DON.

Regression analyses of the sorted and unsorted DON concentrations are presented in Figure 6 for the instances of one sort and two successive sorts. The single- and dual-sort regression lines intersect the critical point of $2 \mathrm{mg} / \mathrm{kg}$ (i.e., the assumed upper limit for unmilled wheat) at the presort levels of 3.8 and $5.7 \mathrm{mg} / \mathrm{kg}$, respectively.

\section{DISCUSSION}

Whereas high-speed optical sorting of seeds has found routine use in certain commodities such as pistachios, beans, peanuts, and rice (24), inroads of this technology applied to wheat handling have been stymied by obstacles of high volume of grain and high cost of sorting equipment. In the United States, current law permits grain handlers and processors to reduce DON contaminant levels through blending of affected grain with clean grain.

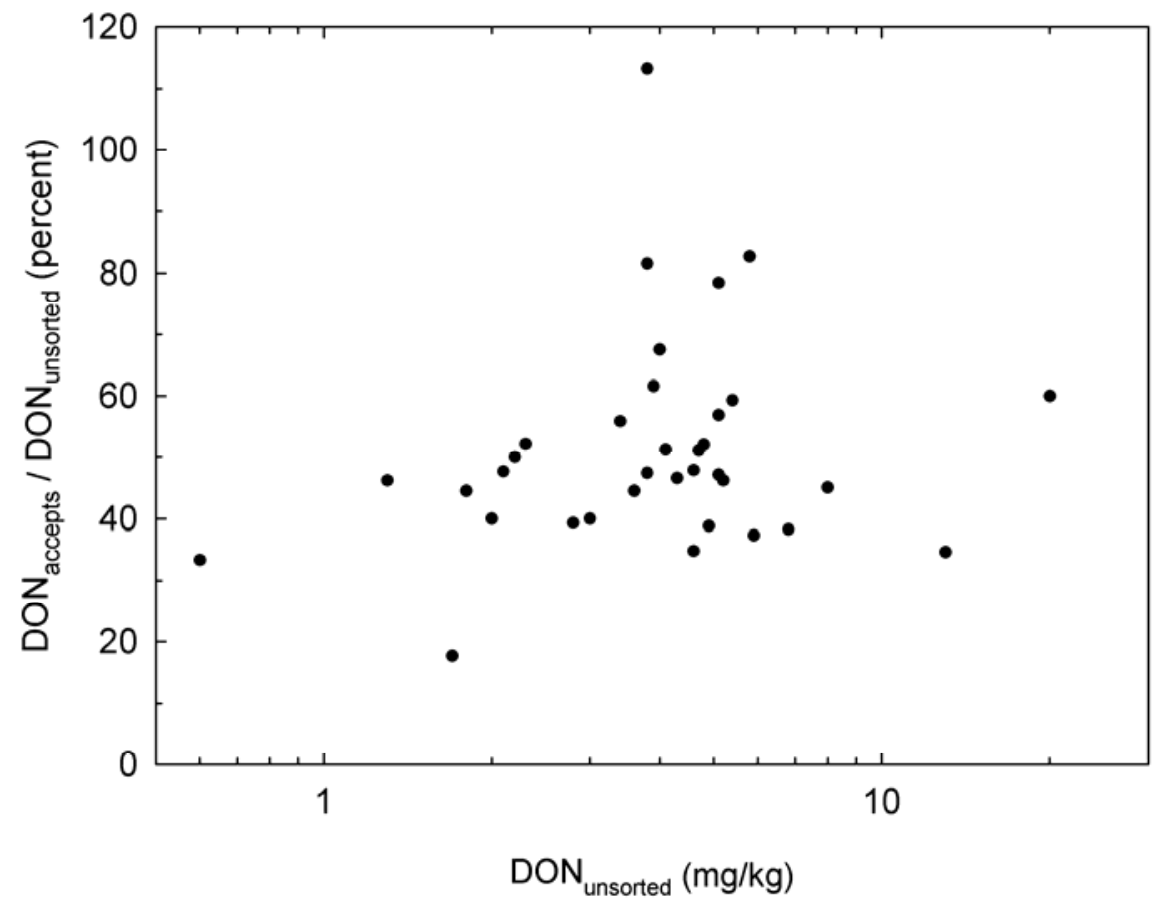

Fig. 3. Efficiency of one-pass sorting for removal of Fusarium-damaged kernels, defined as the ratio of deoxynivalenol (DON) concentration of accepts to the DON concentration of the unsorted (incoming) kernels.

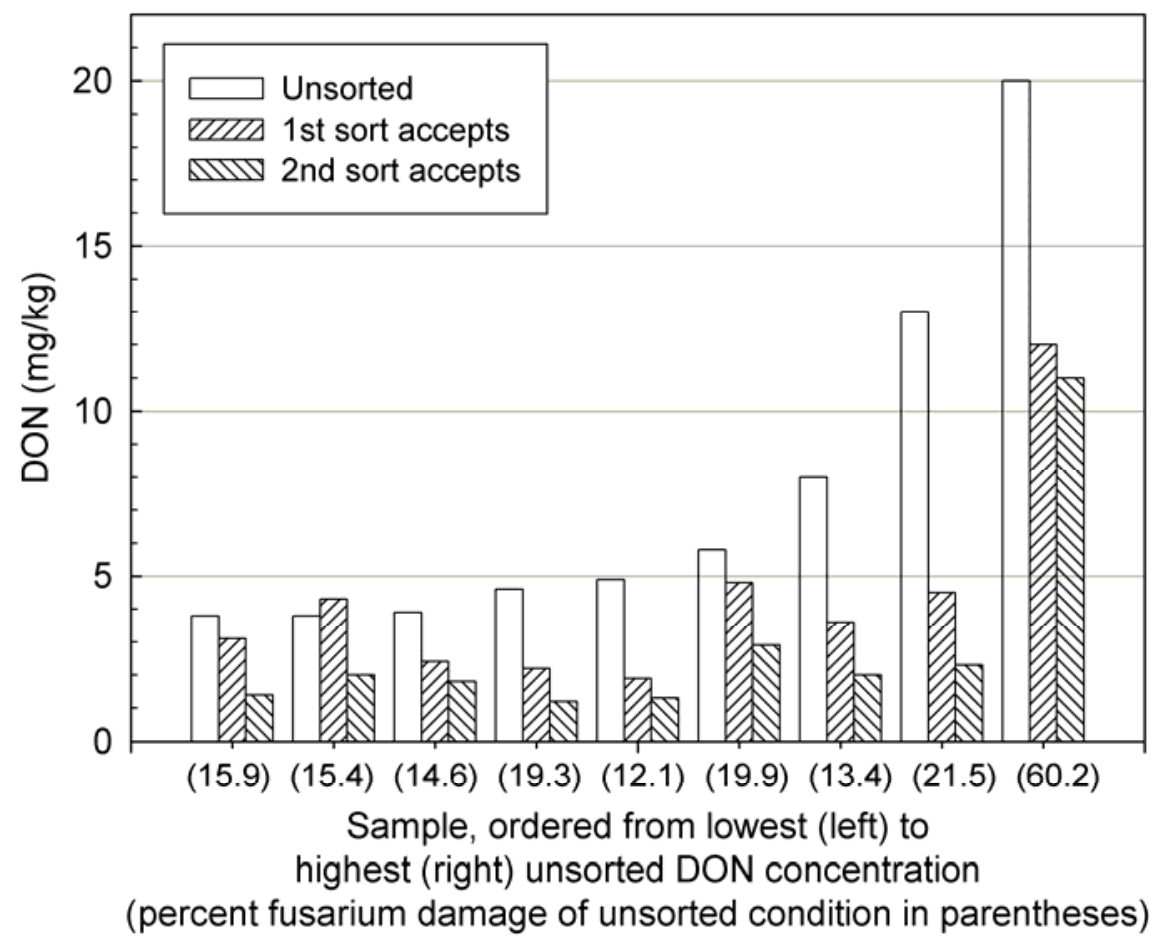

Fig. 4. Effect on deoxynivalenol (DON) concentration of recycling accepts for additional sorting. 
This solution is the least expensive, owing to a lack of need for new equipment (assuming that handlers already possess the machinery to blend grain), and to the fact that all grain is preserved. Therefore, under current law, adoption of optical sorting by the grain industry is unlikely. However, the economic benefits of FDK removal could become apparent should the U.S. Food and
Drug Administration begin to regulate this mycotoxin by establishment of action levels.

Traditionally, high-speed optical sorters are outfitted with sensors and filters that are sensitive to visible light within one wavelength region; hence the designation "monochromatic sorter". In recent years, sorter manufacturers have introduced

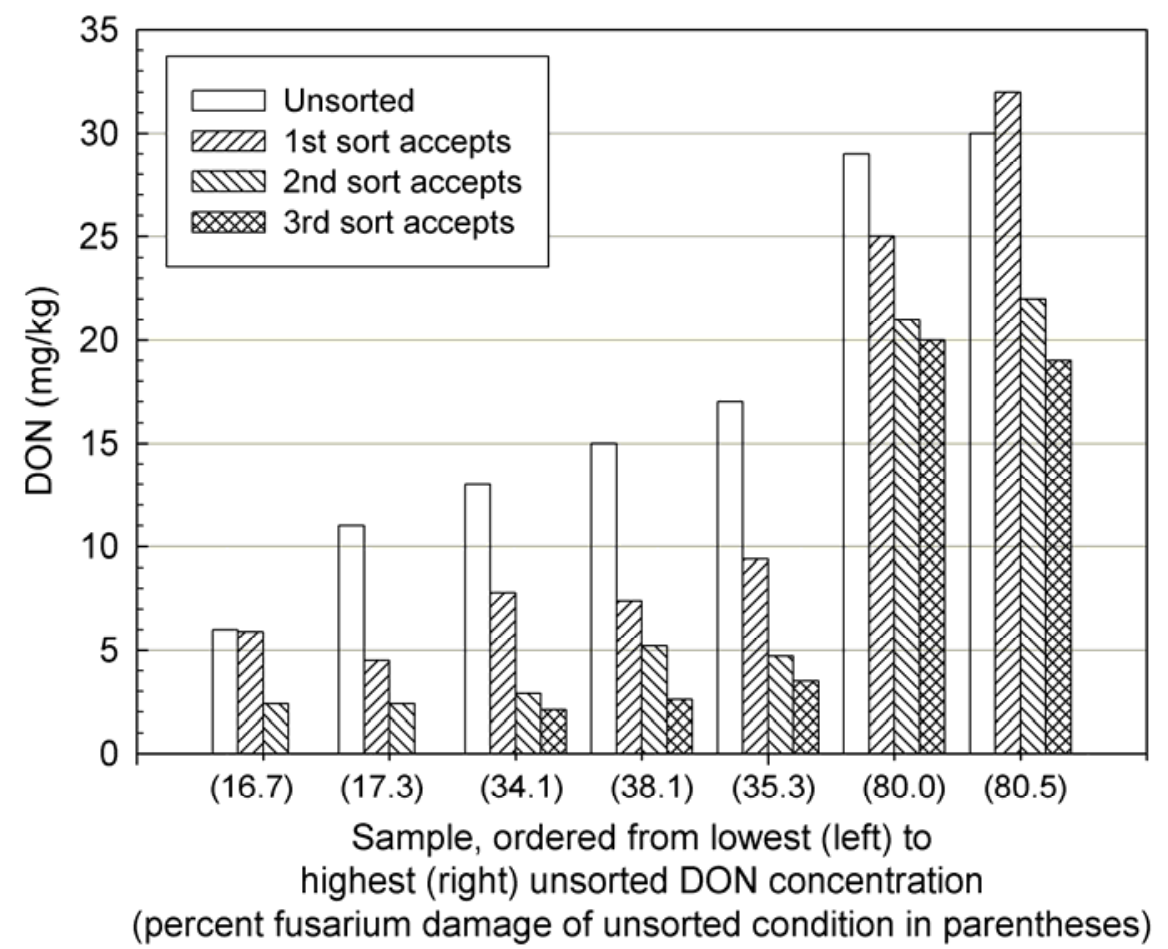

Fig. 5. Effect on deoxynivalenol (DON) concentration of recycling on heavily damaged kernels.

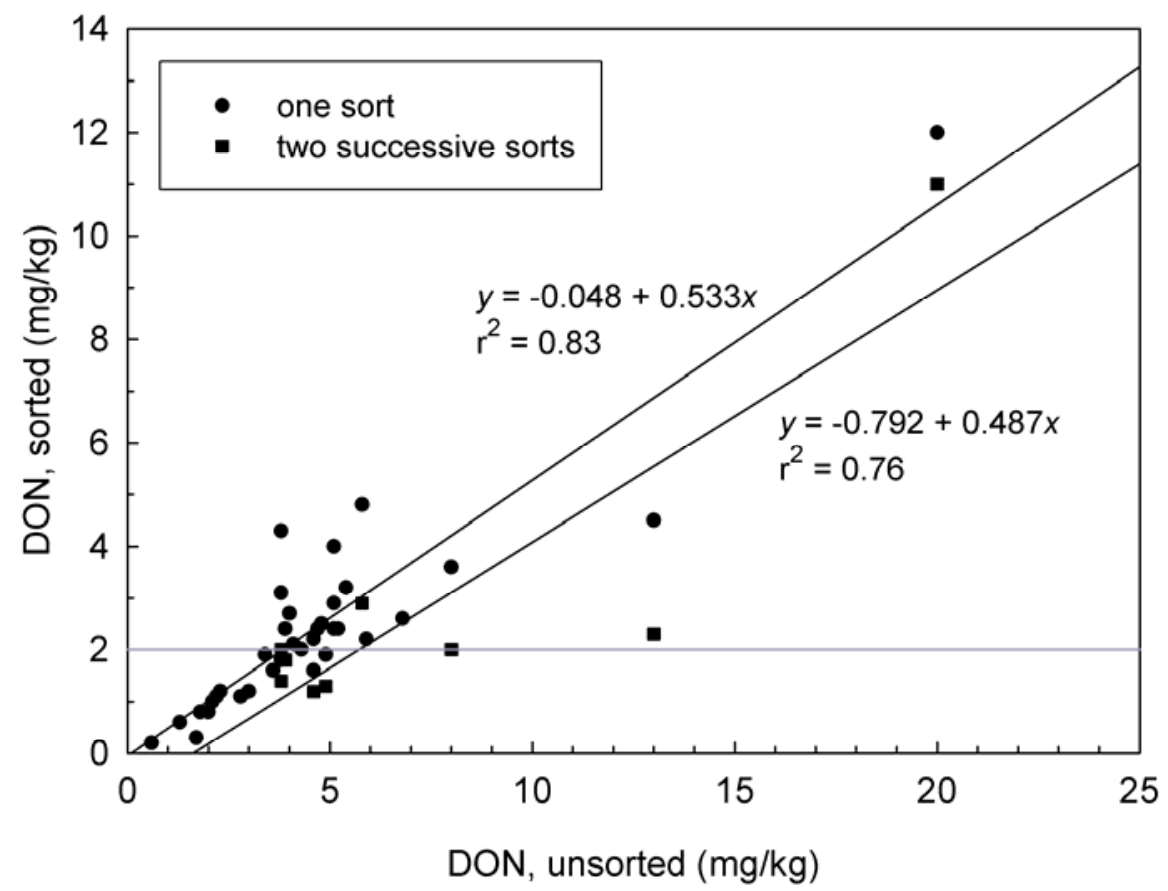

Fig. 6. Regression analysis of the resulting deoxynivalenol (DON) concentration after one and two passes through a high-speed sorter. Model: $\mathrm{DON}_{\text {sorted }}=a_{0}+a_{1} * \mathrm{DON}_{\text {unsorted }}$, where $a_{0}$ is the sorted concentration at zero unsorted concentration, and $a_{1}$ is the change in sorted concentration per unit change in unsorted concentration.

bichromatic machines, in which an additional sensor and filter is utilized. Commonly in the near-IR region, the second sensor is reasoned to be sensitive to differences in biochemical composition (proteins, carbohydrates, and lipids, primarily). This added sensitivity has been recently examined for separation of low- and highprotein seeds (19). The success in the current study may therefore be due to a change in starch (3) or protein composition (4) that is sensed by the near-IR detector.

Delwiche and Gaines (8) reported an $87 \%$ rate of accuracy in recognizing FDK by visible and near-IR spectroscopy, based on wavelengths (750 and 1,476 nm) similar to those used in the present study. This accuracy rate was deemed to be conservative, owing to the use of two separate but nonstandardized spectrometers. However, this value can be compared with the derived accuracy values of the high-speed sorting trials, in which accuracy is defined as the mass ratio of rejects FDK to unsorted FDK, expressed as a percentage: FDK mass $=($ FDK fraction from visual inspection) $\times$ (total material mass). This procedure was applied to every sample of the 35 regular samples whose unsorted material FDK percentage was less than the preset machine rejection rate (approximately 10\%). Based on 26 qualifying samples, accuracy ranged from 23 to $90 \%$, with an average of $45.9 \%$ ( $\mathrm{std}=18.3 \%$ ). Thus, on average, with the settings used herein $(675 \mathrm{~nm}, 1,480 \mathrm{~nm}$ wavelengths, $10 \%$ rejection rate, feed rate $=0.33$ $\mathrm{kg} /[$ min-channel], one pass), high-speed sorting removed approximately one-half the mass of FDK.

Assume that a commercial mill is faced with reducing the DON contaminant level of whole grain wheat to a value that, while in excess of the $1.0 \mathrm{mg} / \mathrm{kg}$ food advisory level, would result in the finished flour having less than this limit. If the assumption is made that conventional milling practices can reduce DON by one-half (a traditional rule of thumb of the industry), the task becomes finding the highest acceptable DON level in whole grain wheat, such that after one or more passes through a high-speed optical sorter the concentration is reduced to no more than $2 \mathrm{mg} / \mathrm{kg}$. Our results indicate that a concentration of $<3.8 \mathrm{mg} / \mathrm{kg}$ on average would be sufficient for a one-sort operation at a $10 \%$ rejection rate. For two passes, each set at $10 \%$ rejection, the allowable concentration rises to $<5.7 \mathrm{mg} / \mathrm{kg}$. Hence, high-speed optical sorting for reduction in DON in commercial wheat is a potentially feasible method when concentrations are in the 2 to 5.7 $\mathrm{mg} / \mathrm{kg}$ range. Such sorting may have even greater utility in plant breeding. For example, in the sorting of white wheat for removal of red kernels, Pasikatan and Dowell (18) noted a 27 and $42 \%$ reduction in red kernels when the rejection rate was changed from 15 to 20 and $25 \%$, respec- 
tively. In these cases, the value gained from a cleaned product far exceeds the loss from rejected grain; such rejection rates greater than $10 \%$ can be used to enhance grain cleanliness.

In summary, high-speed optical sorting was studied for its ability to reduce the concentration of deoxynivalenol (DON) in Fusarium-infected soft red winter wheat. Commercial wheat samples of low $(<1.0$ $\mathrm{mg} / \mathrm{kg}$ ) to very high $(>20 \mathrm{mg} / \mathrm{kg})$ DON were sorted by the simultaneous analysis of two wavelengths, one visible $(675 \mathrm{~nm})$ and one near-IR $(1,480 \mathrm{~nm})$, at a feed rate of $0.33 \mathrm{~kg} /($ min-channel) and a mass rejection rate (preset for each sample) of $10 \%$. On average, with one-pass sorting, the DON concentration of the sorted wheat was $51 \%$ of the original concentration. Successive passes were successful at further reducing the concentration of DON.

\section{ACKNOWLEDGMENTS}

We thank B. Stetzler (ARS, Beltsville) for visual analysis of kernels, M. Eustrom (USDA/GIPSA/ FGIS, Kansas City, MO) for variety identification, and L. Polston (USDA/GIPSA/FGIS, Kansas City, $\mathrm{MO})$ for DON analysis and the anonymous milling companies that contributed damaged wheat.

\section{LITERATURE CITED}

1. Atanasoff, D. 1920. Fusarium-blight (scab) of wheat and other cereals. J. Agric. Res. 20:1-32.

2. Bai, G., and Shaner, G. 1994. Scab of wheat: Prospects for control. Plant Dis. 78:760-766.

3. Bechtel, D. B., Kaleikau, L. A., Gaines, R. L., and Seitz, L. M. 1985. The effects of Fusarium graminearum infection on wheat kernels. Cereal Chem. 62:191-197.

4. Boyacioglu, D., and Hettiarachchy, N. S. 1995. Changes in some biochemical components of wheat grain that was infected with Fusarium graminearum. J. Cereal Sci. 21:57-62.

5. Codex. 2003. Discussion paper on deoxynivalenol. Codex Committee on Food Additives and Contaminants, 35th Session (Arusha, Tanzania, March 17-21, 2003). Codex Alimentarius Commission, FAO/WHO, Rome, Italy.
6. Cunfer, B. M. 1987. Bacterial and fungal blights of the foliage and heads of wheat. Pages 528-541 in: Wheat and Wheat Improvement. 2nd ed. E. G. Heyne, ed. ASA, CSA, and SSA, Madison, WI.

7. Delwiche, S. R. 2003. Classification of scab and other mold-damaged wheat kernels by near-infrared reflectance spectroscopy. Trans. ASAE 46:731-738.

8. Delwiche, S. R., and Gaines, C. S. 2005. Wavelength selection for monochromatic and bichromatic sorting of Fusarium-damaged wheat. Appl. Eng. Agric. 21:681-688.

9. Delwiche, S. R., and Hareland, G. A. 2004. Detection of scab damaged hard red spring wheat kernels by near-infrared reflectance. Cereal Chem. 81:643-649.

10. Dexter, J. E., Clear, R. M., and Preston, K. R. 1996. Fusarium head blight: Effect on the milling and baking of some Canadian wheats. Cereal Chem. 73:695-701.

11. Dexter, J. E., and Nowicki, T. W. 2003. Safety assurance and quality assurance issues associated with Fusarium head blight in wheat. Pages 420-460 in: Fusarium Head Blight of Wheat and Barley. K. J. Leonard and W. R. Bushnell, eds. American Phytopathological Society, St. Paul, MN.

12. Dowell, F. E., Boratynski, T. N., Ykema, R. E., Dowdy, A. K., and Staten, R. T. 2002. Use of optical sorting to detect wheat kernels infected with Tilletia indica. Plant Dis. 86:1011-1013.

13. Dowell, F. E., Ram, M. S., and Seitz, L. M. 1999. Predicting scab, vomitoxin, and ergosterol in single wheat kernels using nearinfrared spectroscopy. Cereal Chem. 76:573576.

14. FAO. 2004. Worldwide regulations for mycotoxins in food and feed in 2003. Food and Nutrition Paper 81, Food and Agriculture Organization of the United Nations, Rome, Italy.

15. Hart, L. P. 1998. Variability of vomitoxin in truckloads of wheat in a wheat scab epidemic year. Plant Dis. 82:625-630.

16. Horwitz, W. 1988. Protocol for the design, conduct and interpretation of collaborative studies. Pure Appl. Chem. 60:855-864.

17. Luo, X., Jayas, D. S., and Symons, S. J. 1999. Identification of damaged kernels in wheat using a colour machine vision system. J. Cereal Sci. 30:49-59.

18. Pasikatan, M. C., and Dowell, F. E. 2003.
Evaluation of a high-speed color sorter for segregation of red and white wheat. Appl. Eng. Agric. 19:33-38.

19. Pasikatan, M. C., and Dowell, F. E. 2004 High-speed NIR segregation of high- and low protein single wheat seeds. Cereal Chem. 81:145-150.

20. Pearson, T. C., Wicklow, D. T., and Pasikatan, M. C. 2004. Reduction of aflatoxin and fumonisin contamination in yellow corn by highspeed dual wavelength sorting. Cereal Chem. 81:490-498.

21. Pomeranz, Y., Bechtel, D. B., Sauer, D. B., and Seitz, L. M. 1990. Fusarium head blight (scab) in cereal grains. Pages 373-433 in: Advances in Cereal Science and Technology. Vol. X. Y. Pomeranz, ed. American Association of Cereal Chemists, St. Paul, MN

22. Rotter, B. A., Prelusky, D. B., and Pestka, J. J. 1996. Toxicology of deoxynivalenol (Vomitoxin). J. Toxicol. Environ. Health 48:1-34

23. Ruan, R., Ning, S., Song, A., Ning, A., Jones, R., and Chen, P. 1998. Estimation of Fusarium scab in wheat using machine vision and a neural network. Cereal Chem. 75:455-459.

24. Satake-USA. 2001. ScanMaster High Capacity Sorters. Satake-USA Corp., Houston, TX.

25. Seitz, L. M., Eustace, W. D., Mohr, H. E., Shogren, M. D., and Yamazaki. 1986. Cleaning, milling, and baking tests with hard red winter wheat containing deoxynivalenol. Cereal Chem. 63:146-150.

26. Stack, R. W. 2003. History of Fusarium head blight with emphasis on North America. Pages 1-34 in: Fusarium Head Blight of Wheat and Barley. K. J. Leonard and W. R. Bushnell, eds. American Phytopathological Society, St. Paul, MN.

27. Tkachuk, R., Dexter, J. E., Tipples, K. H., and Nowicki, T. W. 1991. Removal by specific gravity table of tombstone kernels and associated trichothecenes from wheat infected with Fusarium head blight. Cereal Chem. 68:428431.

28. U.S. Food and Drug Administration. 1993. Letter from Ronald Chesemore to State Agricultural Directors, State Feed Control Officials, and Food, Feed and Grain Trade Organizations on Advisory Levels for DON (vomitoxin) in Food and Feed. U.S. Department of Health and $\mathrm{Hu}$ man Services, Public Health Service. September 16th, Rockville, MD. 